\title{
The Analysis of Pipeline's Penetration Laid on the Elastic-Plastic Seabed Based on the ABAQUS Software
}

\author{
Ren Yanrong ${ }^{1}$, Liu Yubiao ${ }^{2}$ \\ ${ }^{1}$ Science School, Beijing Institute of Civil Engineering and Architecture, Beijing 100044, China \\ ${ }^{2}$ Institute of Mechanics, Chinese Academy of Sciences, Beijing100080, China
}

Keywords: submarine pipeline, stability, Ramberg-Osgood model, penetration

\begin{abstract}
The pipeline's stability is the key problem of submarine pipeline's design. In order to supply the theory basis for the pipeline's design, the ABAQUS software has been adopted to analyze the pipe/soil system. The Ramberg-Osgood model has been adopted to simulate the seabed; the contact pair also adopted to simulate the pipe/soil system, the dynamic boundary contact problem of pipe embedded into the seabed has been analyzed. The computation has been operated according to change pipe's subweight, environment load, pipe's diameter, yielding stress and so on. The computation results have shown that these parameters have effects on the pipe's penetration.
\end{abstract}

\section{Introduction}

The on-bottom stability of submarine pipeline is the key problem of submarine pipeline design.

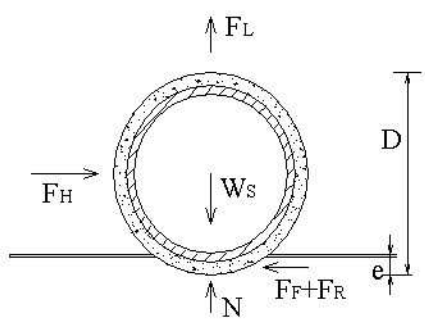

Fig.1 Pipe/soil interaction

Since 1980's, many foreign scientific institutes ${ }^{[1-6]}$ have conducted the further research to the pipe/soil interaction of the untrenched pipe by the cyclic loading. The main conclusions are: the hydrodynamic force induced by wave and current can lead to the pipe's additional penetration, and the soil lateral moundings beneath the pipe will take place when the pipe's lateral displacement happens, these will cause that the soil's lateral resistance to the pipe is larger than Coulomb friction force, so the lateral resistance coefficient larger than Coulomb friction coefficient. They also put forward the pipe/soil interaction model, as shown in Fig.1. In this model, the soil resistance should include a soil passive resistance component as follows:

$$
F_{H}=F_{F}+F_{R}
$$

where $F_{H}$ is total lateral soil resistance, $F_{F}$ sliding resistance and $F_{R}$ lateral passive soil resistance. The above experimental results are reflected in the Veritect's and AGA's design guidelines. ${ }^{[7,8]}$

In recent years, $\mathrm{Gu}$ Xiaoyun and Gao Fuping ${ }^{[9,10]}$ have conducted the pipe/soil interaction experiment under the hydrodynamic force, discussed the physical mechanism definitely besides obtaining the similar results compared to the previous experiments, and also pointed out that the pipeline's instability of the wave-soil-pipe coupling effect is a result of combined action of vortex above the seabed and seepage under the sea bottom, that is to say that the permeability plays an important factor.

The development in numerical computation lags behind that of the experiment. Only Lyons ${ }^{[11]}$ has conducted the computation of the untrenched pipe, adopted nonlinear elastic model and static method. Mei ${ }^{[12]}$ has studied the breakout of half-buried pipe under hydrodynamic force. 
Yongbai ${ }^{[12]}$ has analyzed the on-bottom stability of submarine pipeline, but only concerned with the deformation action of the pipeline, not considering the pipe/soil interaction.

In this paper, the pipe/soil interaction is simulated by using the software ABAQUS ${ }^{[13]}$ program. The pipe/soil system is assumed to be plane strain problem, and the pipe is elastic.

\section{The Choice of Soil's Constitutive Model}

To choosing the soil's constitutive model is the key problem for analzing the stability of pipe and seabed. The load of wave is dynamic because of pipe's laid on the ocean environment. So, the Ramberg-osgood plastic-elastic model has been adopted. The backbone curve of Stress-Strain relationship is as follows:

$$
E \varepsilon=\sigma+\alpha\left(\frac{|\sigma|}{\sigma_{0}}\right)^{n-1}
$$

Among: E-elastic module, $\varepsilon$-strain, $\sigma$-stress, $\sigma_{0}$-yielding stress, $n$-hardening parameter of nonlinear item, $\alpha$-yielding deflection amount.

\section{The Establishment of Finite Model}

Contact Problem. In resolving the pipe/soil interaction, the shearing slip can occur between the contact surface pipe and seabed. In the contact simulation of ABAQUS, the simple master-slave contact method is adopted. In order to obtain better result, the slave and master surface must be chosen carefully, the discipline is: slave surface must be the surface of finer mesh; if mesh density is similar, slave surface must be composed of soft material. Based on this discipline, the lower pipe as master contact surface, two pipe's diameter length on the seabed is chosen to be the slave contact surface, so form a "contact pair".

Finite Element Model and Boundary Conditions. Because the seabed foundation is a semi-infinite space, the certain range should be chosen in the computation. When defining the size of the finite element computation model, the range of the finite element computation model is defined according to the following principles: in horizontal direction the seabed is twenty times of pipe's diameter, vertical is ten times. When analyzing, eight-node element is used for the pipe, the four-node element is used for the seabed, as shown in Fig.2. Boundary conditions are as follows: far away from the pipeline, zero displacements at the both sides, the bottom, however, free boundary is used at the top.

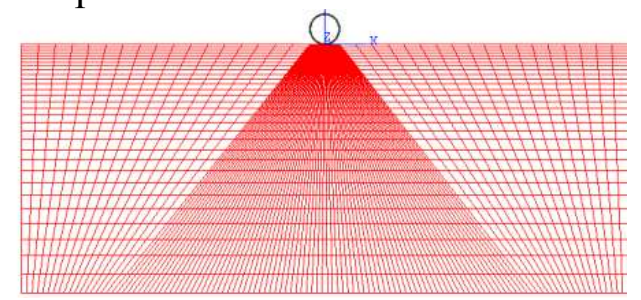

Fig.2 Finite element model

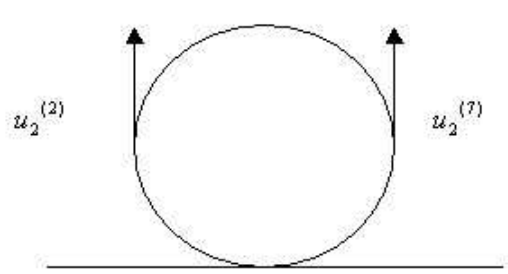

Fig.3 Constraint equation

Constraint Conditions. Because the pipe is constrained by the riser and its rotation stiffness, the pipe can not roll. But in this two dimensional simulation, pipeline has a possibility to roll on the seabed. So the constraint equation is adopted at both sides of the pipe in order to prevent the pipe from rolling, as shown in Fig.3.

The constraint equation is as follows:

$$
u_{2}^{2}+(-1) u_{2}^{7}=0
$$

where, 2 and 7 are the node number of both sides of the pipe separately. 


\section{Computation Results Analysis}

Displacement Field. When pipe's diameter is $1.0 \mathrm{~m}$, pipe's subweight is $11.8 \mathrm{kN} / \mathrm{m}$, the pipe's horizontal displacement isogram graph, vertical displacement isogram graph can be plotted according to the simulation results, the graphs are as follows:

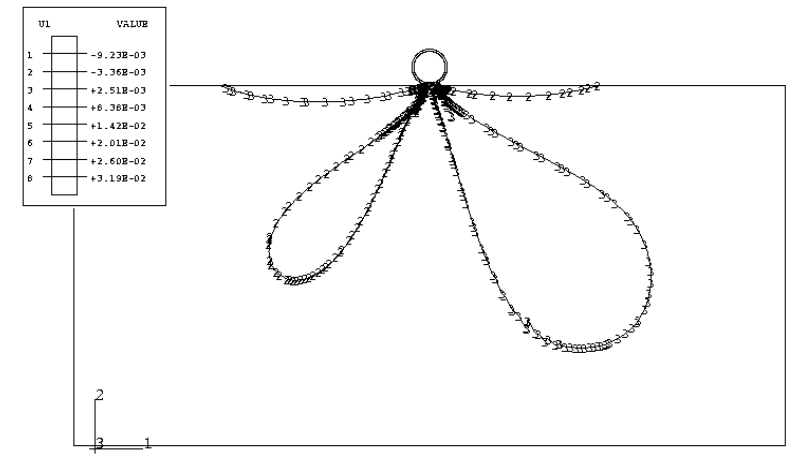

Fig.4 Horizontal displacement

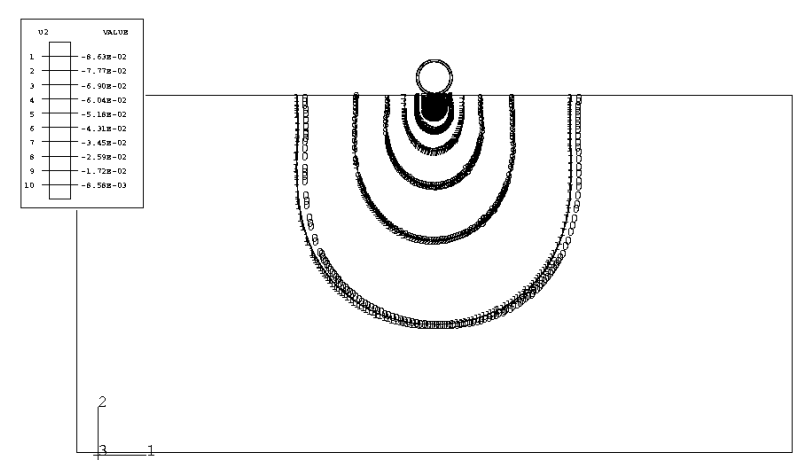

Fig.5 Pipe/soil system vertical isogram graph

From fig.4 and fig.5, we can find that the soil's vertical displacement is bigger near to the pipe, but with the increment of seabed's depth and width, the vertical displacement becomes decreasing and changes to zero at last. But the horizontal isogram not only concentrated on nearing to the pipeline, but also some isogram has been expanded to the fringe of seabed. So the external load has little effect on the soil far from the pipe.

The Effect of Pipe's Subweights. When the horizontal parameters are constant ,changing the pipe's diameter is $0.4,1.0$, the relationship between pipe's penetration and pipe's subweights, the graphs are as follows:

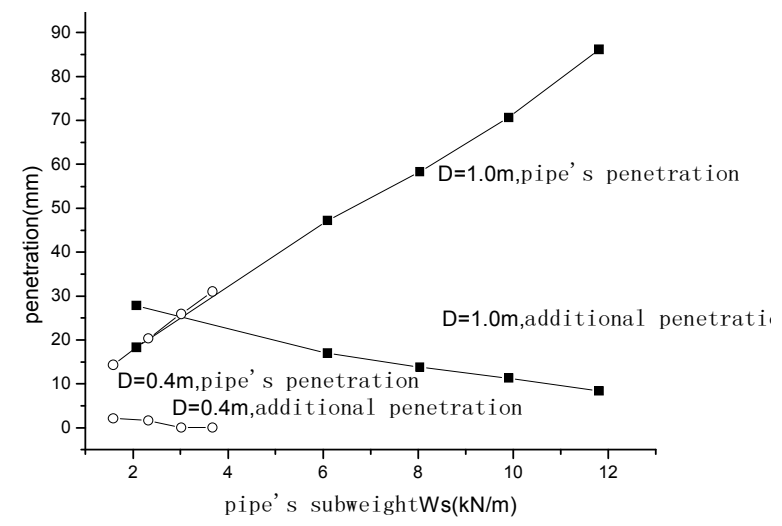

Fig 6. The effect of pipe's subweight

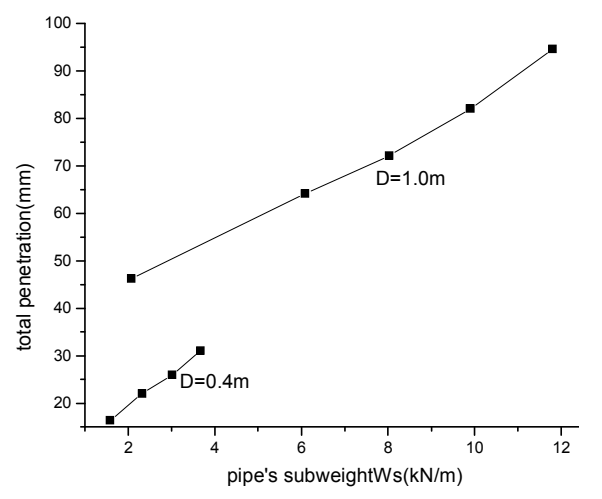

Fig.7 The relationship between the total penetration and pipe's subweight

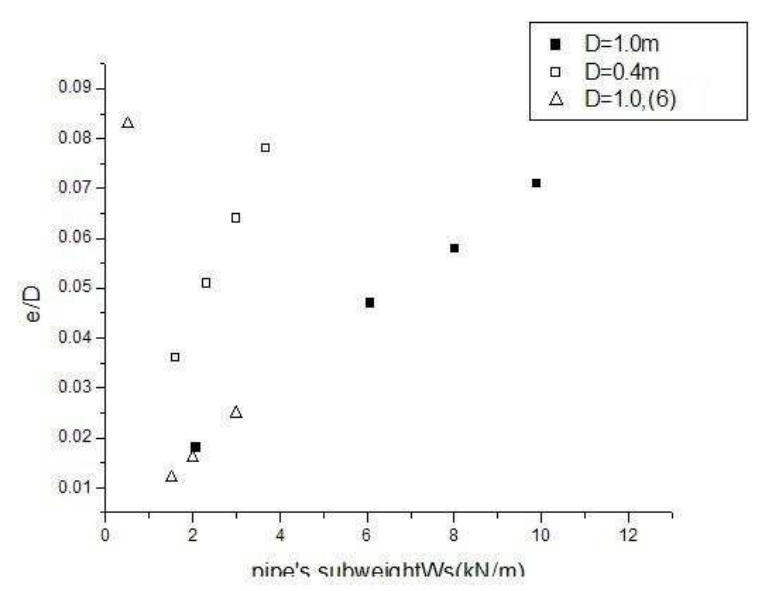

Fig.8 The comparison of pipe's penetration and test results 
From fig.6, it can be found that pipe's penetration is increasing with the subweight's increasment, additional penetration is decreaing with the pipe's subweight's increasement, but total penetration is increaing, see the fig.7. It is because that with the pipe's subweights' increasement, the settlement is increasing, which can cause the horizontal load to the pipe to decrease, the soil's yield stress becomes small, and pipe/soil system reach to the stability, so the additional penetration can't increase. From fig. 8 , the results is compatible with the tests' results ${ }^{[6]}$

The Effect of Environmental Load. When pipe's subweights are constant, the computation has been operated according to change the environmental load, the graphs are as shown in fig.9:

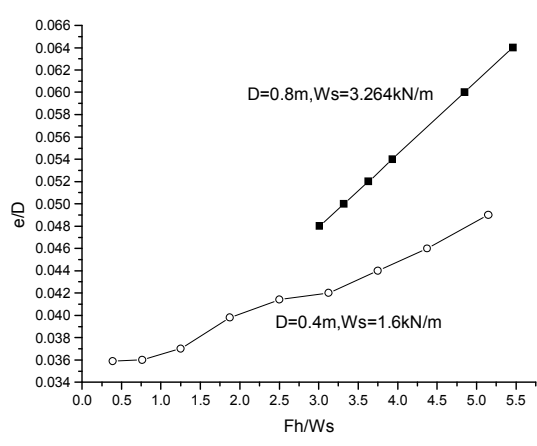

Fig.9 The effect of environmental load

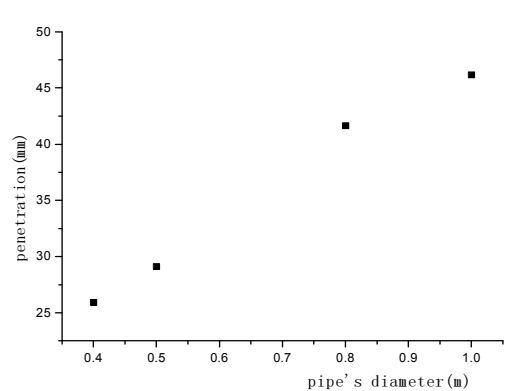

Fig.10 The effect of pipe's diameter

From fig.9, with the environment load increasing, the soil's yield stress also increases, which cause the pipe's total penetration to increase.

The Effect of the Pipe's Diameter. When pipe's subweights is constant, the computation has been operated according to change the pipe's diameter, the graphs are as shown in fig.10.It can be shown from fig. 10 that pipe's penetration increase with the pipe's diameter is increaing.

The Effect of Yielding Stress. For the plastic model, if soil element's stress exceed yield stress, so soil will attach to the yielding status and damage occurs. So the effect of yielding stress has been considered, the graphs are as follows:

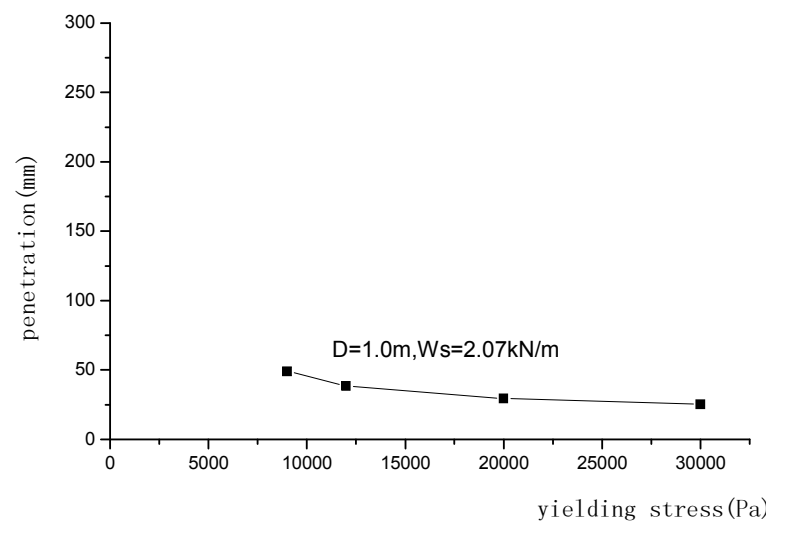

Fig.11 The relationship between penetration and yield stress

It can be shown from fig.11 that with the decreasing of yielding stress, pipe's penetration increases. It is because that yielding stress is smaller, the stress of some elements are easy to get to the yield point, which cause soil to damage, so the pipe's penetration increase。

\section{Summaries}

(1) Because the seabed is elastic-plastic,so there is elasitic deformation and plastic deformation after loading,and the external load is dynamic. So the Ramberg-Osgood is adpoted as soil's constitutive relationship. 
(2) It is feasbile to adopte the ABAQUS software to simulate pipe/soil system. At the same time, it can be shown that the pipe's subweights, environmental load, pipe's diameter, yielding stress have some effects on pipe's penetration.

\section{Reference}

[1]H.Brennodden,O.Sveggen,Full-scale pipe/soil interaction tests[J].OTC Paper 5338,1986.

[2]D.A.Wanger,J.D.Murff,H.Brennodden,"Pipe-Soil Interaction model”,Proceedings of Nineteenth Annual Offshore Technology Conference[J],1987, paper OTC 5504:181-190.

[3]A.C.Palmer,"Lateral Resistance of Marine Pipelines on Sand",Proceedings of $20^{\text {th }}$ Annual Offshore Technology Conference[J],1988,Paper OTC5853:399-408.

[4]D.W.Allen, W.F.Lammert et al.,"Submarine Pipeline On-Bottom Stability:Recent AGA Research", Proceedings of $21^{\text {st }}$ Annual Offshore Technology Conference[J],1989,Paper OTC 6055:121-132.

[5]H.Brennodden,J.T.Lieng,T.Sotberg,R.L.P.Verley.An energy-based pipe/soil interaction model[J].OTC paper 6057, 1989.

[6]Det norske Veritas.On-bottom stability design of submarine pipeline,Recommended Practice 305[M], 1988.

[7]J.R.Hale,W.F.Lammert et al Pipeline On-bottom Stability Calculations:Comparison of two state-of-the art methods and pipe-soil Verification,Proceedings of $23^{\text {rd }}$ Annual Offshore Technology Conference[J],1991,Paper OTC 6761: 567-581.

[8]Gu Xiaoyun, Gao Fuping, Pu Qun. Wave-soil-pipe coupling effect upon submarine pipeline on-bottom stability[J].Acta Mechanica Sinica (English Series) 2001,17(1):86-96.

[9] Gao fuping, Gu xiaoyun, Puqun, Experimental research on the instability process of submarine pipelines[J], Chinese Journal of Geotechnical Engineering,2000, 22 (3) , 304-308.

[10]C.G.Lyons,"Soil Resistance to Lateral Sliding of Marine Pipelines", Proceedings of Fifth Annual Offshore Technology Conference[J],1973, Paper OTC 1876:479-484.

[11]Mei CC.,Foda M F. Wave-induced Stresses around a Pipe laid on a Poroelastic Seabed. Geotechnique[J], 1981b,31:09-517.

[12]Yong Bai et al.,"A fininte-Element Model for In-Situ Behavior Offshore Pipelines On Uneven Seabed and Its Application to On-Bottom Stability",Proc. $9{ }^{\text {th }}$ Int.Offshore and Polar Engineering Conference[J], 1999,Vol.IIPP. 132-140.

[13] ABAQUS6.6 Standard User's Manual[M]. 
Material and Manufacturing Technology IV

10.4028/www.scientific.net/AMR.748

The Analysis of Pipeline's Penetration Laid on the Elastic-Plastic Seabed Based on the ABAQUS Software

10.4028/www.scientific.net/AMR.748.416 